17. Laurell, C.-B.: Quantitative estimation of proteins by electrophoresis in agarose gei containing antibodies. Anal. Biochem., 15: 45 (1966).

18. Laurell, C.-B.: Relation between structure and biologic function of the protease inhibitors in the extracellular fluid. In: H. Peeters: Protides of the Biological Fluids. In: Proceedings of the Twenty-Second Colloquium, p. 3 (Pergamon Press, New York, 1974).

19. Lillie, R. D.: Histopathologic Technic and Practical Histochemistry. (McGrawHill Book Company, Inc., New York, 1965).

20. Matsubara, S., Yoshida, A., and Lieberman, J.: Material isolated from normal and variant human liver that immunologically crossreacts with alpha ${ }_{1}$-antitrypsin. Proc. Nat. Acad. Sci. U. S. A., 7l: 3334 (1974).

21. Peters, T., Jr., Fleischer, B., and Fleischer, S.: The biosynthesis of rat serum albumin. IV. Apparent passage of albumin through the Golgi apparatus during secretion. J. Biol. Chem., 246: 240 (1971).

22. Ritchie, R. F., Alper, C. A., Graves, J., Pearson, N., and Larson, C.: Automated quantitation of proteins in serum and other biologic fluids. Amer. J. Clin. Pathol., 59: 151 (1973).

23. Sharp, H. L.: $\alpha_{1}$-Antitrypsin deficiency, Hosp. Pract., 6: 83 (1971).

24. Sharp, H. L., Bridges, R. A., Krivit, W., and Preier, E. F.: Cirrhosis associated with $\alpha_{1}$-antitrypsin deficiency: A previously unrecognised inherited disorder. J. Lab. Clin. Med., 73: 934 (1969).

25. Talamo, R. C., Langley, C. E., Reed, C. E., and Makino, S.: $\alpha_{1}$-Antitrypsin deficiency: A variant with no detectable $\alpha_{1}$-antitrypsin. Science, 181: 70 (1973)

26. Talamo, R. C., Levison, H., Lynch, M. J., Hercz, A., Hyslop, N. E., and Bain, H. W.: Symptomatic pulmonary emphysema in childhood associated with

Copyright (c) 1976 International Pediatric Research Foundation, Inc. hereditary $\alpha_{1}$-antitrypsin and elastase inhibitor deficiency. J. Pediat., 79: 20 (1971).

27. Westbrook, Me.

28. Ames Co., Elkart, Ind

29. Behring Diagnostics, Inc., Woodbury, N. Y

30. Cappel Laboratories, Inc., Downington, $\mathrm{Pa}$

31. Microbiological Associates, Bethesda, Md.

32. Falcon Plastics, Oxnard, Calif.

33. New England Nuclear Corp., Boston, Mass.

34. We thank Dr. Lisbeth Brendstrup for assistance in preparation of the electron micrographs, and the physicians and staff of the Clinical Research Center for the care of the patients during study.

35. The present address of Dr. A. K. Bhan is: Department of Pathology, Massachusetts General Hospital, Boston, Mass. 02114

36. Dr. R. J. Grand is recipient of Academic Career Development Award AM 44590 from the National Institute of Arthritis, Metabolism and Digestive Diseases.

37. Dr $\mathrm{H}, \mathrm{R}$. Colten is recipient of United States Public Health Service Career Development Award 1-K4-HD-GM 70,558

38. This research was supported by United States Public Health Service Grants nos AM 14523, Al 11419, HD 05916, and AM 13855 and Clinical Research Center Grant no. FR-128.

39. Requests for reprints should be addressed: H. R. Colten, M.D., Allergy Division, The Children's Hospital Medical Center, 300 Longwood Ave., Boston, Mass. 02115 (USA).

40. Accepted for publication August 15, 1975 .

Pediat. Res. 10: 40-45 (1976)

Arterial blood pressure

heart rate

hypothalamus

Printed in U.S.A.

\title{
Cardiovascular Effects of Electrical Stimulation of the Forebrain in the Fetal Lamb
}

\author{
ROBERT L. WILLIAMS, ROBERT P. HOF, MICHAEL A. HEYMANN, ${ }^{(28)}$ AND ABRAHAM M. \\ RUDOLPH \\ Cardiovascular Research Institute and Department of Pediatrics, University of California, \\ San Francisco, California, USA
}

Extract

Modified stereotaxic techniques were applied to fetal lambs during the latter third of gestation. Electrical stimulation in the region of the hypothalamus in $\mathbf{1 0}$ acute experiments was associated with three patterns of arterial blood pressure and heart rate changes: a pressor-tachycardia response; a pure tachycardia response (abolished by propranolol); and a pure bradycardia response (abolished by atropine). The pressor-tachycardia response was examined in detail in 13 chronic preparations (115-135 days of gestation at operation). The systolic arterial blood pressure increase was never greater than $35 \mathrm{~mm} \mathrm{Hg}$ and was probably blunted by the large noninnervated placental circulation. This pressure increase was abolished by phentolamine and was thus mediated by stimulation of $\alpha$-adrenergic receptors. The initial tachycardia was prevented by propranolol and was due to $\beta$-adrenergic stimulation. The tachycardia was followed in a few seconds by a bradycardia, abolished by atropine and possibly a vagal baroreflex. The pressortachycardia response was accentuated in two lambs who were delivered spontaneously and were studied after birth. These studies indicate that a suprabulbar neural framework exists in the fetal lamb for influencing the cardiovascular system from as early as $\mathbf{9 0}$ days of gestation.
Speculation

Since electrical stimulation in the region of the hypothalamus is associated with various changes in blood pressure and heart rate, it is possible that the upper brain stem in the late gestation fetus has a role in the central nervous regulation of the circulation. Complex cardiovascular patterns may be organized in this region in response to fetal stress.

Although most experiments on central nervous regulation of the circulation have been performed in mature animals, there is evidence that the fetal and neonatal cardiovascular systems are also under central autonomic control. Resting sympathetic and parasympathetic influences on the heart and blood vessels of the fetal lamb are present by 0.55 gestation $(20)$. Baroreflex $(4,17)$ and chemoreflex (7) responses can be elicited after 0.60 gestation and the nervous pathways almost certainly involve the lower brainstem. Gootman et al. (11) observed blood pressure and heart rate changes with electrical stimulation of the brainstem in anesthetized newborn piglets.

The developmental pattern of central nervous influences on the fetal circulation has not been studied although the above examples 
would support at least an active "vasomotor center" in the lower brainstem. We examined the functional efficacy of another central component of the autonomic nervous system to identify and document the maturation of an area which might participate in the mediation or modulation of fetal cardiovascular responses. We studied the region of the hypothalamus because it contains areas which influence the circulation in adult animals and definite nuclei and fiber tracts can be identified in the forebrain of the fetal lamb from 0.60 gestation (2). Experiments were performed both acutely and in fetal lambs maintained chronically in utero to circumvent the effects of general anesthesia on cardiovascular reflex responses (5) and to obviate the effects of acute exteriorization (13).

\section{METHODS}

Two groups of time dated mixed breed Western or Dorset ewes were studied; 10 fetuses (90-145 days of gestation) acutely and 13 (115-135 days of gestation at operation) chronically 3-30 days after recovery from surgery.

Spinal anesthesia ( $2 \mathrm{ml}$ of $1 \%$ tetracaine- $\mathrm{HCl}$ ) was given to the ewe and a catheter placed in her saphenous vein. The uterus was exposed through a midline incision, a small hysterotomy performed, and a vinyl catheter inserted into a fetal hindlimb artery. All fetal incisions were made after infiltration with $0.5 \%$ lidocaine $\mathrm{HCl}$. The hindlimb was returned and the hysterotomy closed. A second uterine incision was made over the fetal neck and catheters placed in the carotid artery and jugular vein, care being taken to avoid the vagosympathetic trunk. Fetal carotid or femoral arterial blood pressure was measured with a Statham P23Dc transducer and recorded continuously on a direct writing recorder (Beckman type R Dynograph). Instantaneous heart rate was obtained with a cardiotachometer from the arterial pulse interval.

Intravenous pentobarbital $(100-200 \mathrm{mg})$ was administered to the ewe and then $5 \mathrm{mg} / \mathrm{kg}$ of gallamine triethiodide (8) was slowly infused into the fetal jugular vein. Fetal drug doses were based on estimated weights at various gestational ages (1). The fetal head was delivered through the uterine incision and inserted into a modified stereotaxic apparatus (22).

Stereotaxic coordinates of the hypothalamus are available for adult sheep (21) but not for fetal lambs. Since both the size and configuration of the fetal head change with advancing gestation, the three-dimensional coordinates of any given brain area are a function of fetal age. We therefore established reference coordinates for lambs of various gestational ages. The anterior margin of the optic chiasma in the midline was chosen as a reference site because of its proximity to the anterior hypothalamus and its stereotaxic coordinates were determined in 30 fetal skulls of known external dimensions.

During the present experiments, fetal external skull measurements were made and, by referring to the previously constructed charts, the horizontal and vertical stereotaxic coordinates of the anterior optic chiasma predicted. These coordinates, although not exact, allowed the exploratory electrode to be inserted into the region of the hypothalamus; the precise location was always verified by subsequent histologic examination.

The dura was exposed through a small craniotomy and an insulated unipolar stainless steel electrode (tip diameter $150 \mu \mathrm{m}$ ) advanced near the midline into the forebrain. The indifferent electrode (always the anode) was buried in the long muscles of the neck. Trains of monophasic square waves, were delivered from a Grass S4 stimulator and SIU4 stimulus isolation unit. Current intensity and wave form were monitored on a Tektronix RM 654 storage oscilloscope and altered electrode tip impedance was detected by distortion of the square wave. The usual parameters of the 10 -sec stimulation train were: frequency $=80(5-100) \mathrm{Hz}$; duration $=2$ msec; and, current $=200-1,000 \mu \AA$.

Once the electrode had been inserted into the region of the hypothalamus, stimulation was performed while advancing in increments of $1 \mathrm{~mm}$. In these acute explorations the number of penetrations varied from 2 to 8 (mean 5) and each penetration was more caudal than the preceding to avoid damage to descending pathways. Carotid arterial blood gases and $\mathrm{pH}$ were measured during the experiments using standard Radiometer electrodes and blood gas analyzer and the results reported are from stimulations when the carotid arterial blood $\mathrm{pO}_{2}$ was $>20$ torr, $\mathrm{pCO}_{2}<45$ torr, and $\mathrm{pH}>7.32$.

In four of the fetuses studied acutely (120-135 days of gestation) a left lateral thoracotomy was performed before the head was exposed and an electromagnetic flow transducer placed around the main pulmonary trunk. The chest was closed, the fetal head was then brought out through the uterine incision, and an electrode was placed in the region of the hypothalamus as described previously. Right ventricular stroke volume (obtained by integrating the phasic output of the flowmeter (Statham SP 7515)) was recorded continuously during diencephalic stimulation.

In one fetus studied acutely at 140 days of gestation a bilateral adrenalectomy was performed through flank incisions after placement of the forebrain electrode.

Catheters and a stimulating electrode were similarly placed aseptically in 17 fetuses. In these an additional catheter was inserted into the trachea through a purse string suture and advanced as far as the thoracic inlet. By using the coordinates determined during the acute experiments, no more than two electrode penetrations were necessary to find an area where diencephalic stimulation was associated with changes in blood pressure and heart rate. Once found, the electrode was fixed rigidly in place with dental cement (NuWeld) which bonded to the electrode, the skull, and the heads of four small screws driven into the calvarium approximately $1 \mathrm{~cm}$ from the shaft of the electrode (Fig. 1). One of the screws served as the indifferent electrode. The scalp was closed, the head returned, a catheter placed in the amniotic cavity and fluid which had escaped during the procedure replaced with warm sterile saline. All catheters and wires were exteriorized to the ewe's flank and protected by a Teflon pouch. The catheters were filled with sodium heparin (1000 USP units/ $\mathrm{ml})$ and flushed every $48 \mathrm{hr}$. Potassium penicillin G $(2,500,000$ units) and kanamycin $(0.5 \mathrm{gm})$ were administered intravenously to the ewe after the operation and every $48 \mathrm{hr}$ for the first six postoperative days.

The animals were allowed to recover for 2 days after surgery. Thirteen fetuses satisfied the previously described blood gas and $\mathrm{pH}$ criteria and were studied chronically. Electrical stimulation of the fetal diencephalon was performed after intravenous administration of $5 \mathrm{mg} / \mathrm{kg}$ gallamine triethiodide when fetal arterial blood pressure and heart rate were stable and there was no fetal or

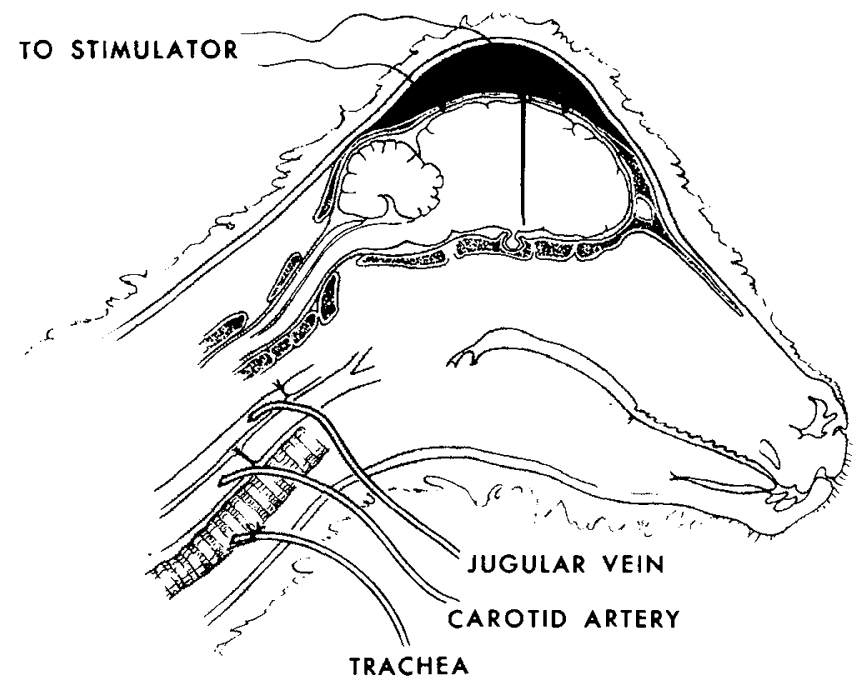

Fig. 1. Sagittal section of the head of a chronic fetal lamb preparation showing placement of the electrode and catheters. 
maternal movement evident on the tracheal or amniotic cavity pressure tracings. Amniotic cavity and fetal tracheal and carotid or femoral arterial blood pressure and heart rate were recorded before, during and after diencephalic stimulation using similar electrical parameters as during the acute studies.

Two fetuses delivered spontaneously with catheters and electrodes intact and were studied both before and 3-15 days after birth when nursing normally and gaining weight. These postnatal experiments were performed with the lambs sedated lightly by intravenous administration of $0.5 \mathrm{mg} / \mathrm{kg}$ diazepam.

The effects of autonomic blockade on the various components of the cardiovascular responses to forebrain stimulation were studied. $\alpha$-Adrenergic blockade was obtained by intravenous administration of phentolamine $(100 \mu \mathrm{g} / \mathrm{kg})$, sufficient to abolish the pressor effect of methoxamine $(50 \mu \mathrm{g} / \mathrm{kg}), \beta$-adrenergic blockade by propranolol $(1 \mathrm{mg} / \mathrm{kg})$ sufficient to block the positive chronotropic effect of isoproterenol $(0.05 \mu \mathrm{g} / \mathrm{kg})$, and parasympathetic blockade by atropine sulfate $(0.2 \mathrm{mg} / \mathrm{kg})$, which abolished the transient bradycardia associated with the injection of acetylcholine (15 $\mu \mathrm{g} / \mathrm{kg}$ ). Phentolamine was not given on the same day as propranolol or atropine to ensure complete recovery from $\alpha$ blockade.

The exact location of the stimulation points were determined histologically in all but two chronic preparations in which advanced postmortem changes had occurred. The brain was fixed by perfusion with saline and buffered formalin. Ten-micron serial sections were cut in the same plane as the electrode tracts and stained with hematoxylin and eosin.

\section{RESULTS}

In the 10 acute studies, 47 vasoactive loci were identified in 53 penetrations. These loci were restricted to reasonably discrete areas of the brain since the response to stimulation was almost always lost when the electrode tip was moved by $1 \mathrm{~mm}$. Three specific patterns of arterial blood pressure and heart rate changes were observed; (1) pressor-tachycardia; (2) tachycardia; and, (3) bradycardia. The loci from which they were elicited are shown in Figure 2. It was possible for more than one response to be seen during a single acute experiment.

The pressor-tachycardia response was the most frequent produced (66\% of responses) and was observed at all gestational ages. (In the chronic animals this was the only response studied as the electrode was cemented in place only after these changes were elicited.) It was characterized by an increase in both systolic and diastolic arterial blood pressure of 8-35 (mean 18) $\mathrm{mm} \mathrm{Hg}$. The maximum rise never exceeded $35 \mathrm{~mm} \mathrm{Hg}(20 \mathrm{~mm} \mathrm{Hg}$ in fetuses less than 100 days of gestation) even when current intensity was increased many times above threshold. This blood pressure elevation was not sustained but decreased after about 6-8 sec despite continued stimulation. Heart rate increased from 20-60 (mean 37) beats/min but also fell after $6-8 \mathrm{sec}$ of stimulation and continued to fall as low as 40 beats/min below control. Blood pressure and heart rate returned to baseline 10-30 sec after cessation of stimulation and the magnitude of the late bradycardia was related directly to the degree of elevation of systolic blood pressure. Figure 3 is from a fetus in which right ventricular stroke volume was also measured. In all four the pressor-tachycardia response was associated with an initia! small decrease in right ventricular stroke volume of from 0.2 to 0.9 (mean 0.5 ) $\mathrm{ml}$ but this rapidly increased simultaneously with the late bradycardia. The pressor-tachycardia responses in the chronic studies were the same as those obtained acutely except that the initial increase in heart rate was greater (from 28-90 (mean 49 ) beats/min).

The next most frequent pattern (23\% of responses) was the tachycardia response (Fig. 4) which was observed at all gestational ages. Stimulation produced heart rate increase from $10-60$ (mean 42) beats/min, unassociated with any major (greater than $8 \mathrm{~mm}$ $\mathrm{Hg}$ ) increase in arterial blood pressure. When the increase in heart rate was greater than 30 beats/min, there was, however, a small decrease in systolic blood pressure probably related to diminished stroke volume. Unfortunately, this response was not elicited in any of the experiments in which main pulmonary trunk blood flow was measured.

The third pattern (11\% of the responses) was the bradycardia response characterized by a decrease in heart rate from $10-50$ (mean 37) beats/min without a major (greater than $8 \mathrm{~mm} \mathrm{Hg}$ ) change in arterial blood pressure (Fig. 5). This was observed only in fetuses of more than 130 days of gestation. The bradycardia was

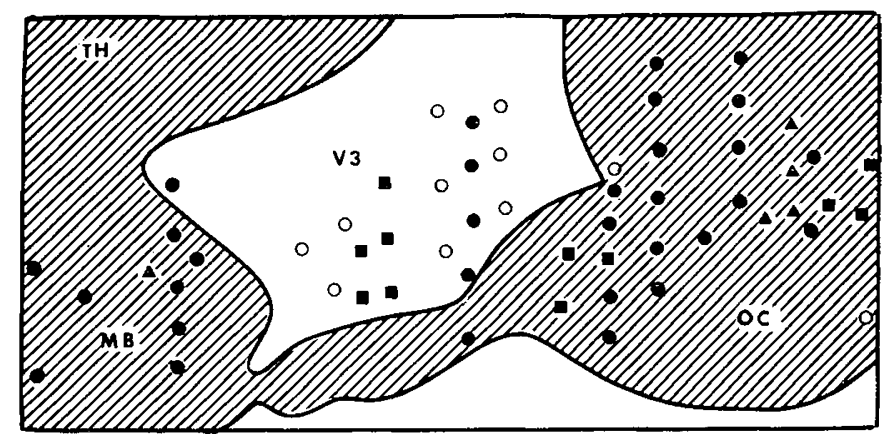

(a)

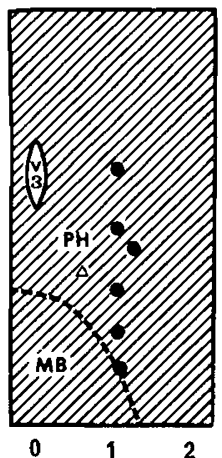

(b)

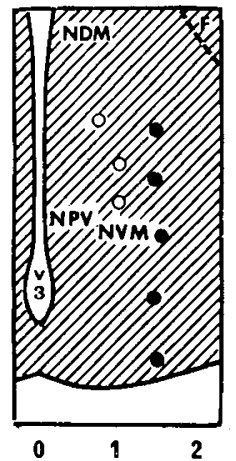

(C)

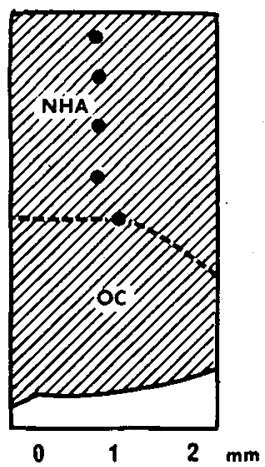

Fig. 2. A schematic composite midline sagittal section in the region of the hypothalamus and three coronal sections $a, b$, and $c$, showing loci which are associated with blood pressure and heart rate responses on electrical stimulation. Chronic experiments in open and acute experiments in shaded symbols: pressor-tachycardia $(\boldsymbol{\bullet})$; tachycardia $(\boldsymbol{\square})$; and, bradycardia $(\mathbf{\Lambda})$ responses. $M B$ : mamillary bodies; $N D M$ : nucleus dorsomedialis; $N H A$ : nucleus hypothalamus anterior; $N P V$ : nucleus periventricularis; $N V M$ : nucleus ventromedialis; $O C$ : optic chiasma; $P H$ : posterior hypothalamus; $T H$ : thalamus; V3: third ventricle.

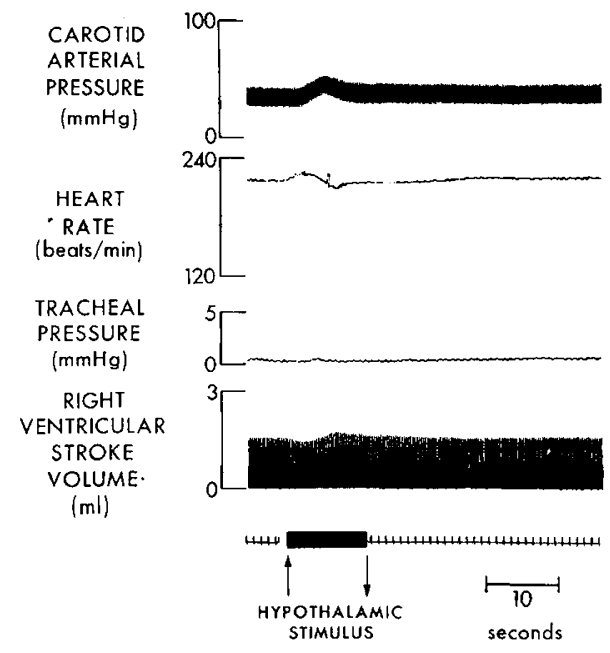

Fig. 3. The carotid arterial blood pressure, heart rate, tracheal pressure, and right ventricular stroke volume recorded during $10-\mathrm{sec}$ electrical diencephalic stimulation in a 132-day gestation acute fetal lamb preparation demonstrating the pressor-tachycardia response. 
not sustained and heart rate began to return to baseline after 1-3 sec despite continued stimulation.

There was a latent period of $1-4 \mathrm{sec}$ between the beginning of stimulation and the onset of both the pressor-tachycardia and tachycardia responses. The bradycardia response always had a more rapid onset with a latent period of $1 \mathrm{sec}$ or less. The blood pressure latency was always greater than the heart rate latency in the pressor-tachycardia response. In one acute experiment the latency $(1.5 \mathrm{sec})$ and the magnitude of the pressor-tachycardia response was identical before and $35 \mathrm{~min}$ after bilateral adrenalectomy.

The intensity of threshold current for the three cardiovascular responses varied from 200 to 800 (mean 600) $\mu \AA$ except in three fetuses whose gestational ages were less than 100 days and in whom the current necessary to elicit a response was approximately $50 \%$ greater. In addition, there were fewer vasoactive sites (only 5 in 16 penetrations) found during the acute mapping experiments in these younger fetuses and the arterial blood gases and $\mathrm{pH}$ deteriorated more rapidly.

In the chronic preparations the threshold current required for the pressor-tachycardia response was $300-500 \mu \AA$ lower $2-3$ days after surgery than it was during the implantation. In six fetuses studied from 3-5 days after operation current strength was kept

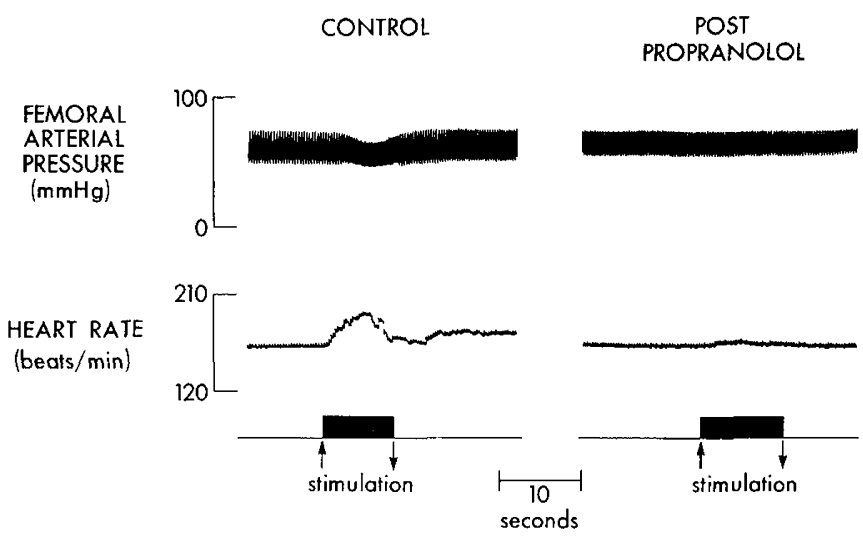

Fig. 4. The femoral arterial blood pressure and heart rate recorded during $10-\mathrm{sec}$ electrical diencephalic stimulation in a 128-day gestation acute fetal lamb preparation demonstrating the tachycardia response before and after the administration of $1 \mathrm{mg} / \mathrm{kg}$ propranolol.

CONTROL
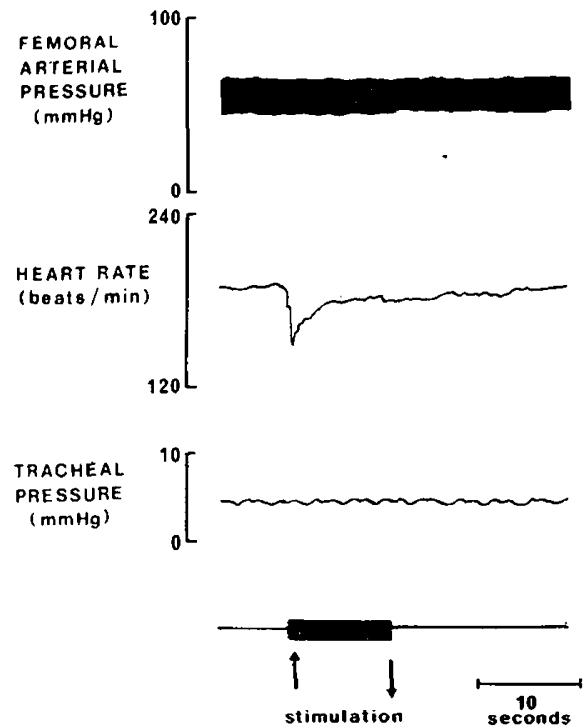

Fig. 5. The femoral arterial blood pressure, heart rate, and tracheal pressure recorded during 10 -sec electrical diencephalic stimulation in a 137 -day gestation acute fetal lamb preparation demonstrating the bradycardia response before and after the administration of $0.2 \mathrm{mg} / \mathrm{kg}$ atropine.
$200 \mu \AA$ above threshold and the duration of the square wave constant at $2 \mathrm{msec}$ as frequency was increased stepwise from 5 to $100 \mathrm{~Hz}$ while stimulating for $10 \mathrm{sec}$ every $2 \mathrm{~min}$. The threshold $\mathrm{Hz}$ and increasing the frequency changed the magnitude but not the character of the response. It was of particular interest that lower frequencies were not associated with depressor responses. cardia response was studied in 10 chronic lamb preparations from 122 to 144 days' gestation. Administration of phentolamine produced a $0-8$ (mean 3.5$) \mathrm{mm} \mathrm{Hg}$ decrease in resting mean arterial blood pressure and a transient increase in heart rate. When electrical stimulation was repeated using identical parameters, the initial increase in pressure of the pressor-tachycardia response was abolished $(P<0.001$, paired $t$-test $)$. The initial increase in heart rate was not affected; however, when blood pressure did not increase, there was no late bradycardia (Fig. 6).

Complete $\beta$-adrenergic blockade produced a 9-28 (mean 16) beat/min decrease in resting heart rate in seven chronic lamb preparations (121-136 days of gestation) and abolished $(P<$

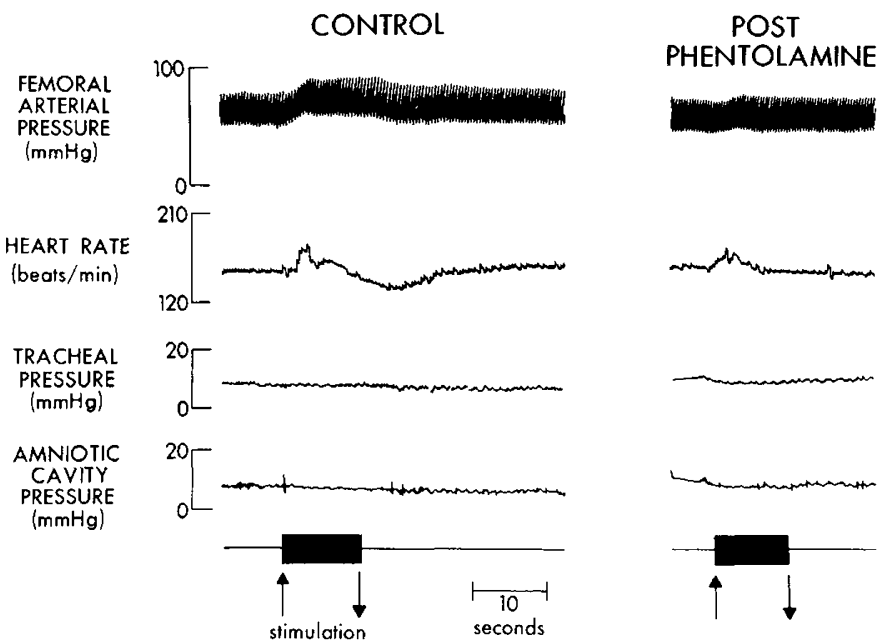

Fig. 6. The femoral arterial blood pressure, heart rate, tracheal, and amniotic cavity pressure recorded during 10 -sec electrical diencephalic stimulations in a 124-day gestation chronic fetal lamb preparation before and after administration of $100 \mu \mathrm{g} / \mathrm{kg}$ phentolamine. frequency for the pressure-tachycardia response was from 40-50

The effects of $\alpha$-adrenergic blockade on the pressor-tachy-

POST ATROPINE 


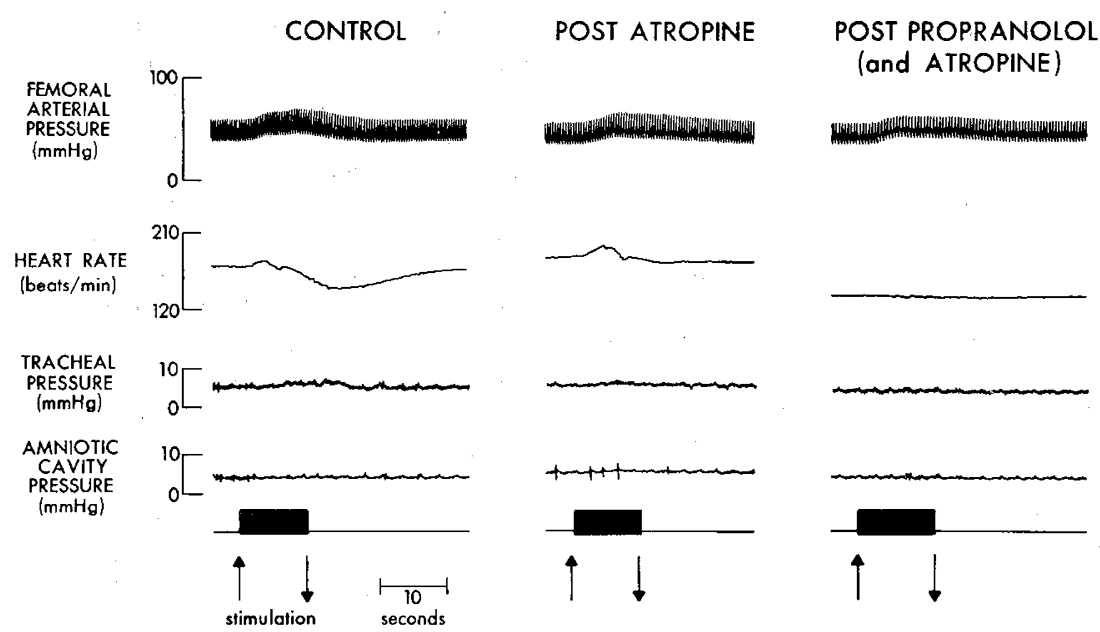

Fig. 7. The femoral arterial blood pressure, heart rate, tracheal pressure, and amniotic cavity pressure recorded during 10 -sec electrical diencephalic stimulation in a 132-day gestation chronic fetal lamb preparation during a control period, after atropine and after propranolol and atropine.

$0.001)$ the initial tachycardia of the pressor-tachycardia response. The studies involving $\beta$ sympathetic and vagal blockade were usually performed on successive days; however (Fig. 7), the drugs were administered during the course of one day's experiment. The tachycardia response in the acute experiments was also obliterated by $\beta$ blockade (Fig. 4).

Complete vagal blockade was obtained in eight chronic lamb preparations of $122-137$ days of gestation. The resting heart rate was 9-36 (mean 17) beats/min faster after atropine and the late bradycardia of the pressor-tachycardia response was abolished $(P$ $<0.001$ ) (Fig. 7). Atropine also completely prevented the bradycardia response in two acute experiments (Fig. 5).

The arterial $\mathrm{pO}_{2}$ in the two newborn lambs was greater than 85 torr and resting systemic arterial pressure and heart rate were about $50 \%$ greater than in the same lambs in utero. Forebrain stimulation was performed applying similar parameters as had been used in the same animal in utero $48 \mathrm{hr}$ before delivery. The changes in blood pressure and heart rate were associated with an alerting type of behavior: the lambs raised their heads, looked around and there was moderate pupillary dilatation. A short latency pressor-tachycardia response was observed and the maximum increase in blood pressure $(60 \mathrm{~mm} \mathrm{Hg})$ was much greater than in utero.

\section{DISCUSSION}

These studies demonstrate that, with certain modifications, classic stereotaxic techniques can be applied to the study of circulatory responses to electrical stimulation of the forebrain in the fetal lamb. In many respects the responses to stimulation were similar to those reported from acute experiments in anesthetized mature animals; however, striking differences were apparent which may contribute to the understanding of fetal circulation.

The pressor-tachycardia response, the most frequent change observed, produced a maximal increase in arterial blood pressure never greater than $35 \mathrm{~mm} \mathrm{Hg}$ even with supramaximal currents of stimulation. This increase is modest when compared with that associated with hypothalamic stimulation in adult anesthetized animals; however, it is impressive when considered in the context of the fetal circulation. Approximately $40 \%$ of fetal cardiac output perfuses the low resistance placenta (16) and it is possible that this very compliant vascular bed buffers increases in fetal arterial blood pressure. The pressor-tachycardia response persisted in two newborn lambs in whom resting arterial blood pressure and heart rate were about $50 \%$ greater than in utero. Stimulation produced the pressor-tachycardia response with a greater increase in pressure than in utero. This might be related to elimination of the placental circulation, a more mature sympathoadrenal system or removal of inhibitory mechanisms that might have been operating in utero. It is also possible that the "set point" of cardiovascular reflex mechanisms may be different before and after birth as described by Biscoe et al. (3) for the carotid body chemoreflex. In contrast to mature cats, the arterial blood pressure elevation persisted for only a few seconds and returned toward baseline even as stimulation continued. This may have been due to excitation of baroreceptors since when the pressor response was blocked by phentolamine there was no late vagal bradycardia. It was not due to exhaustion of effector mechanisms since a similar response was elicited by repeat stimulation several seconds later. The current was continuously monitored during the period of stimulation and showed no decay.

The threshold current required to evoke a response was greater than in adult animals (10) and was clearly greater in lambs under 100 days of gestation than in older fetuses. These differences could be due to maturation of cell membrane excitability or, perhaps, to the concentration of cells and fibers in a specific locus. Intercellular and fiber distances might be greater in fetal than adult brain and a stimulus of the same magnitude would excite fewer cells. It is also possible that the central nervous system of a younger fetal brain may be more sensitive to the small doses of barbiturate used for sedation of the ewe in the acute experiments.

The 1-4-sec latency from onset of stimulation to the initial changes in pressure and heart rate was considerably greater than in adult animals. Since stimulation of the diencephalon in adult cats (9) and the splanchnic nerve in late gestation fetal lambs (6) may be associated with adrenal catecholamine release, it was possible that the delayed responses were due to this mechanism alone. Although catecholamines could be released and possibly reach the fetal heart and peripheral arterial circulation within a 4 -sec period, this is highly unlikely to be responsible for the cardiovascular changes since the responses often had a latency of only one second. Also, the latency and character of the pressor-tachycardia response were similar before and after bilateral adrenalectomy in one acute experiment in a late gestation fetus. We recognize, however, that this may not have ablated all chromaffin tissue in the fetus (e.g., the organ of Zuckerkandl). One could postulate that the relatively long latency of some responses could be due to slower nerve conduction, increased synaptic delay, or slower end-organ responses in the fetus.

Stimulation of the anterolateral hypothalamus of anesthetized adult animals is often associated with depressor responses $(14,15)$; however, a decrease in pressure greater than $8 \mathrm{~mm} \mathrm{Hg}$ was never seen in our acute experiments. The resting sympathetic vasoconstrictor tone in fetal resistance vessels may be less than in mature animals for resting blood pressure decreased only minimally after the administration of phentolamine and the pressure never fell 
below prestimulation values during the recovery phase of the pressor-trachycardia response. The small decrease in blood pressure could also be related to the buffering effect of the placental circulation. It is also possible that the depressor areas in the fetal forebrain develop much later than pressor areas or are perhaps under inhibitory influences in utero. The threshold frequency for the pressor-tachycardia response was from $40-50 \mathrm{~Hz}$ and decreasing below this value was never associated with conversion to a depressor response as in the adult cat (12). It would seem that the fetal cardiovascular system may be protected against neurogenic hypotension mediated at a hypothalamic level. Alternatively, the acute preparation in this instance, requiring slight doses of barbiturate to sedate the ewe, may have modified the background discharge of sympathetic nerve fibers and hence reduced the amount of neurogenic tone. However, since intermittent doses of barbiturate used to sedate the ewe in the acute experiments did not alter mean arterial blood pressure in the fetus, this would suggest that sympathetic tone was not affected in the fetus.

The histologic localization of the areas involved in the various patterns of response can be interpreted only in a general fashion because of the relatively small number of loci positively identified and the problems inherent in comparing our results with published maps from adult anesthetized animals. The species studied, the type and depth of anesthesia, baseline cardiovascular values, and the frequency and intensity of stimulation all affect the type of response elicited from stimulation in specific areas of the forebrain. The pressor-tachycardia response was elicited from widespread areas in the region of the fetal hypothalamus. Fairly well localized areas were present which selectively activated sympathetic cardioacceleratory (tachycardia response) and vagal cardioinhibitory (bradycardia response) mechanisms with minimal changes in arterial blood pressure. It is known that diencephalic stimulation in mature animals produces not only generalized sympathoadrenal activation but complex and selective patterns of cardiovascular changes $(18,19)$. We did not examine distribution of blood flow to individual organs but the fact that arterial blood pressure changes occurred suggests that the capability of the hypothalamus to regulate the circulation is already developed by 0.6 gestation in the fetal lamb. The changes in right ventricular stroke volume could be due to changes in heart rate and it is unlikely that hypothalamic stimulation had any direct effect on myocardial performance.

It would be incorrect at present to assign the role of centers to these areas in the fetal forebrain for it is uncertain whether the responses seen are due to activation of afferent or efferent pathways, internuncial connections, or areas where the response is organized. It is conceivable that some of the loci stimulated may facilitate or inhibit patterns of cardiovascular change that are, in fact, organized elsewhere. Cardiovascular alterations associated with hypothalamic stimulation indicate only that potential nervous pathways exist and give little information of their physiologic role. It is possible that only bulbar and/or spinal vasomotor areas control the fetal circulation and that suprabulbar mechanisms, although anatomically intact, are of minor functional importance. Although the complexity of the central nervous system precludes any but the most naive explanation of the results of central stimulation, these studies indicate that supramedullary areas do exist which upon stimulation from 0.6 gestation are associated with complex patterns of cardiovascular change. Many aspects of these responses are clearly different from those in mature animals and their further study may lead to a better understanding of the functional maturation of those central component of the autonomic nervous system associated with cardiovascular control.

\section{REFERENCES AND NOTES}

1. Barcroft, J.: Researches on Pre-Natal Life (Blackwell Scientific Publications, Oxford, 1946)

2. Barlow, R. M.: The foetal sheep: Morphogenesis of the nervous system and histochemical aspects of myelination. J. Comp. Neurol., 135: 249 (1969).

3. Biscoe, T. J., Purves, J. J., and Sampson, S. R.: Types of nervous activity which may be recorded from the carotid sinus nerve in the sheep foetus. J. Physiol. 202: 1 (1969).

4. Brinkman, C. R., III, Ladner, C., Weston, P., and Assali, N. S.: Baroreceptor functions in the fetal lamb. Amer. J. Physiol., 217: 1346 (1969).

5. Brown, R. V., and Hilton, J. G.: The effectiveness of the baroreceptor reflexes under different anesthetics. J. Pharmacol. Exp. Ther., /18: 198 (1956).

6. Comline, R. S., and Silver M.: The release of adrenaline and noradrenaline from the adrenal glands of the foetal sheep. J. Physiol. 156: 424 (1961).

7. Dawes, G. S.: Fetal autonomy. In: G. E. W. Wolstenholme and M. O'Connor: Ciba Foundation Symposium, (Churchill, London, 1969).

8. Feigl, E. O.: Vasoconstriction resulting from diencephalic stimulation. Acta Physiol. Scand., 60: 372 (1964).

9. Folkow, B., and von Euler, U. S: Selective activation of noradrenaline and adrenaline producing cells in the suprarenal gland of the cat by hypothalamic stimulation. Circ. Res., 2: 191 (1954).

10. Forsyth, R. P.: Hypothalamic control of the distribution of cardiac output in the unanesthetized rhesus monkey. Circ. Res., 26: 783 (1970).

11. Gootman, N., Gootman, P. M., Buckley, N. M., Cohen, M. 1., Levine, M., and Spielberg, R.: Central vasomotor regulation in the newborn piglet, Sus scrofa. Amer. J. Physiol., 222: 994 (1972).

12. Hare, K., and Geohegan, W. A.: Influence of frequency of stimulus upon response to hypothalamic stimulation. J. Neurophysiol., 4: 266 (1941).

13. Heymann, M. A., and Rudolph, A. M.: Effects of exteriorization of the sheep fetus on its cardiovascular function. Circ. Res., 21: 741 (1967).

14. Hilton, S. M., and Spyer, K. M.: Participation of the anterior hypothalamus in the baroreceptor reflex. J. Physiol., 218: 271 (1971).

15. Lofving, G.: Cardiovascular adjustments induced from the rostral cingulate gyrus. Acta Physiol. Scand., 53 (suppl. 184): 1 (1961).

16. Rudolph, A. M., and Heymann, M. A.: Circulatory changes during growth in the fetal lamb. Circ. Res., 26: 289 (1970).

17. Shinebourne, E. A., Vapaavuori, E. K., Williams, R. L., Heymann, M. A., and Rudolph, A. M. Development of baroreflex activity in unanesthetized fetal and neonatal lambs. Circ. Res., 31: 710 (1972).

18. Smith, O. A., Rushmer, R. F., and Lasher, E. P.: Similarity of cardiovascular responses to exercise and to diencephalic stimulation. Amer. J. Physiol., 198: $1139(1960)$.

19. Uvnas, B.: Sympathetic vasodilator system and blood flow. Physiol. Rev., 40 (suppl. 4): 69 (1960).

20. Vapaavuori, R. K., Shinebourne, E. A., Williams, R. L., Heymann, M. A., and Rudolph, A. M.: Cardiovascular responses to autonomic blockade in intact fetal and newborn lambs. Biol. Neonate, 22: 177 (1973).

21. Welento, J., Szteyn, S., and Milart, Z.: Observations on the stereotaxic configuration of the hypothalamic nuclei in the sheep. Anat. Anz. Bd., 124: 1 (1969).

22. Trent Wells, Inc., South Gate, Calif.

23. The authors wish to express their appreciation to Dr. Ralph Forsyth and gratefully acknowledge the skilled technical assistance of Mrs. Christine Roman and Mr. Lesley Williams.

24, Dr. R. L. Williams is a Centennial Fellow of the Medical Research Council of Canada; present address: Departments of Physiology and Pediatrics, McGill University, Montreal, Canada.

25. Dr. R. P. Hof is a Research Fellow of the Bay Area Heart Assocration.

26. Dr. M. A. Heymann is the recipient of Research Career Development Award no. HD 35398 from the National Institute of Child Health and Human Development, National Institutes of Health, Bethesda, Md.

27. This research was supported by United States Public Health Service Program Project Grant no. HL 06285 from the National Heart and Lung Institute, National Institutes of Health. Bethesda, Md

28. Requests for reprints should be addressed to: M. A. Heymann, M.D., Cardiovascular Research Institute, University of California. San Francisco, San Francisco, Calif. 94143 (USA).

29. Accepted for publication August 19, 1975. 